\title{
Bad manners, not good
}

SIR - Your leading article "Good manners win out" (Nature 375, 2; 1995) is, in my opinion, misleading. When grants are awarded by the US Public Health Services, they are awarded to the institution, with responsibility for the work being delegated to the principal investigator. Responsibility for governing access to and publication rights over such research traditionally rests with the institution.

After reviewing the history of the Irish schizophrenia studies to which you refer, it is my opinion that the study was primarily the work of $\mathrm{Dr}$ Kenneth Kendler, although Dr Scott R. Diehl clearly made an important contribution. Kendler, who devised these studies and began them before Diehl's arrival at Virginia Commonwealth University (VCU) should, in my opinion, be a significant author on major papers from this study. Clearly, papers generated by a team of investigators should not be published by a junior member of the team without the inclusion of the team leader.

Shortly after they became aware of the initial findings of linkage to schizophrenia on chromosome 6p in the spring of 1993, Kendler proposed that Diehl should write a paper reporting these results, with Diehl as first author, Kendler as last author and other Irish and VCU investigators as coauthors. Diehl refused this offer, as he did again towards the end of 1994.

The National Institutes of Health (NIH) were never asked by us to adjudicate the issue of access to and publication of the Irish studies. Indeed, the National Institute of Mental Health, the part of NIH that funded the work of Kendler and Diehl, specifically rebuffed Diehl's attempts to gain access to these data, stating that it was VCU's responsibility to decide the matter. Diehl did issue an ultimatum to his colleagues that if we did not agree to his publication plan (which included S. Wang as first author and Diehl as last author), he would publish the results on his own. Both I and the leading Irish collaborator on the project, Dr Dermot Walsh, told Diehl that such action would be inappropriate.

Your choice of title, "Good manners win out", is particularly ironic. Kendler has spent more than ten years building a collaboration with his Irish colleagues and they have collected the largest and most informative linkage study of schizophrenia yet available. Diehl published these data without the permission or knowledge of Kendler, his Irish colleagues or this institution, where the work was carried out. Whereas Kendler, following standard scientific etiquette, kept Diehl informed of his publication plans, Diehl prepared and submitted his manuscript in secret. Kendler has worked scrupulously to ensure proper academic credit to his Irish colleagues, including several young Irish psychiatrists who spent years working on this project, while Diehl's preemptory publication has deprived them of appropriate recognition. A more appropriate title for your leading article would have been "Bad manners win out".

William L. Dewey

Virginia Commonwealth University, PO Box 980568,

Richmond, Virginia 23298-0568, USA

- The alternative title suggested is much better - Editor, Nature.

\section{Science in India}

SIR - Universities have a profound role to play in generating knowledge, as well as transmitting that knowledge from one generation to the next. The responsibility to do this rests squarely on faculty members. At leading UK universities, such as Oxford, Cambridge and Glasgow, it is clear that university lecturers have a distinct role to play in enriching the lives of those they teach. And what is taught must stand up to the scrutiny of the students. It is good quality research that makes the lecturer acceptable to the system.

So what has gone wrong in Indian universities? Financial difficulties, student unrest, non-academic influences both inside and outside the universities all play a part. But none is the root cause of present problems. I am optimistic that things may improve and should like to suggest a remedy.

The most severe blow to academics in Indian universities has resulted from the rapid growth in numbers of so-called professors benefiting from merit promotion schemes that have been arbitrarily applied. The problems will continue if the process is not effectively monitored and reversed. These upstarts create all sorts of problems for younger scientists. For example, they demand co-authorship of research papers for which they hardly deserve even an acknowledgement. This obviously helps those young researchers who agree to co-authorship in the expectation of favours from their superiors.

As professors are usually members of decision-making committees, active researchers can be effectively silenced. And eminent academics from the Indian Institutes of Technology and the national laboratories join these professors in approving $\mathrm{PhD}$ theses in which they have taken no part. Similarly, Indian scientists working abroad connive in this process in order to obtain opportunities to visit Indian institutions. A young scientist working abroad after gaining a bachelor's degree in engineering in India has been known not only to act as an examiner of a $\mathrm{PhD}$ thesis in physics but also to approve it within a fortnight from the date of despatch as if he were anticipating it. Thesis supervisors take undue credit for the work of their protégés. Is this not a form of prostitution?

My belief is that this whole process is the principal cause of the problems in Indian universities. Unproductive academics of the kind I have described outnumber other researchers and are able to humiliate and embarrass them in many ways.

My remedy is to propose that all faculty members should take part in appointing and promoting staff to ensure that people are accountable for their actions. For myself, I have been in academic life for 15 years, having rejected an offer to work with an eminent astronomer in order to take part in academic life, and I love teaching. But I would have welcomed an opportunity of being evaluated for promotion on the basis of my research.

\section{B. N. Dwivedi}

Department of Applied Physics,

Institute of Technology,

Banaras Hindu University,

Varanasi 221005, India

\section{Effects of DDE}

SIR - A leading article in Nature ${ }^{1}$ states that "the major metabolite of DDT, $p, p$ ' DDE, is a demasculinizing agent", and therefore "the case for research to be conducted urgently is overwhelming". It is unlikely that such research could be conducted with human subjects, but information is available on 63 human males exposed to DDT (and hence to DDE) in the DDT manufacturing plant in Torrance, California, with a median of 15 years of exposure ${ }^{2}$. No cases of cancer were found during 19 years of employment. The married male workers averaged four children per family. "The largest families had as many as 13 children" and the (male) supervisor had 8 children (personal communication).

The effects of DDE, $100 \mathrm{mg}$ per $\mathrm{kg}$ per day, on rats described by Kelce et al. ${ }^{3}$ corresponded to 7 grams of DDE per day for a $70 \mathrm{~kg}$ human. This is quite disproportionate to levels of DDE, median about 10 nanograms per $\mathrm{ml}$ of blood, found in humans ${ }^{4}$. Lower levels of DDE had no effect on reproduction in rats or beagle $\operatorname{dogs}^{5,6}$.

\section{Thomas H. Jukes}

University of California, Berkeley,

Oakland, California 94608, USA

1. Nature 375, 522 (1995).

2. Laws, B.R., Curley, A, \& Biros, F. J. Environ. Hith 15 766-775 (1967).

3. Kelce, W R. et al. Nature 375, 581-585 (1995).

4. Wolff, M.S. et al. J. natn. Cancer Inst. 85 (21 April 1993).

5. Ottoboni, A. Toxic. appl. Pharmac. 14, 74-81 (1969).

6. Ottoboni, A. et al. Arch. Envir. Contamination Toxicol. 6, 83-101 (1977). 